\title{
Notas sobre uma literatura vulnerável: El artista sanitário
}

\author{
Antonio Carlos Santos*
}

\begin{abstract}
Resumo: As narrativas de Carlos Ríos nos remetem a uma situação contemporânea que aponta para um esgotamento do paradigma modernista. O objetivo deste texto, é pensar as estratégias de Carlos Ríos, pensar como rearma o sensível de modo a desvelar uma nova noção de comunidade: como habitar o mundo? Como se relacionar com os animais? Como escrever um relato?
\end{abstract}

Palavras-chave: Literatura latinoamericana. Teoria literária. Narrativa.

\begin{abstract}
Ojalá... dentro de todo... Pero no. No era questión de que pasara esto o aquello. Era una combinatoria, o mejor dicho un orden... Los hechos se ordenaban de otro modo... Se repetían... O mejor dicho, derivaban... En los peores momentos me preguntaba a mí misma: estoy loca?

César Aira

A furare normannorum libera nos Domine

Carlos Ríos
\end{abstract}

No texto que escreveu para a contracapa de La biografía ilustrada de Mishima, de Mario Bellatin, Carlos Ríos estabelece uma relação entre as fotos que compõem a metade do livro e o texto que conta a história da vida (?) de Mishima depois do haraquiri, ou seja, a história de um poeta sem cabeça: "las fotografías incluidas en este libro despliegan un espacio paralelo y atraen textos de diferentes épocas que se ativan para refrendar, desde los bordes del enigma, su caráter ritual y profético. Así, la indagación biográfica adquiere un giro inesperado al contrariar la idea de que cada acontecimiento es único para revelarnos rigurosamente que todos los personajes viven siempre una idéntica trama, con diferentes apariencias". Talvez pudéssemos dizer o mesmo do próprio Ríos.

Em El artista sanitario, uma narrativa publicada em 2012, o ritual, o profético "y la misma trama con diferentes apariencias", aparecem já na primeira cena, no primeiro dos 17 fragmentos que compõem o relato. É o ritual da matança de 92 porcos, comandada pelo pulso forte do pai, na granja familiar, em Vestlandet, Noruega, que define a vida do pintor sanitário e que nos levará das terras geladas da Noruega ao México, traçando em poucas linhas uma vida de artista (que poderia ser também encenada desde a série de pinturas holandesas sobre o abate de porcos ou

* Doutor em Literatura pela Universidade Federal de Santa Catarina e professor Programa de Pós-
graduação em Ciências da Linguagem (UNISUL). 
bois até os muralistas mexicanos). As primeiras palavras desta cena são nomes de lugares - Vestlandet (região Oeste), Sogn og Fjordane, condado da Noruega - que nos são dados como indicação em um roteiro. Separada por um espaço em branco, a segunda frase continua a nos dar indicações, desta vez de uma ação: "Matanza de noventa y dos cerdos en la granja familiar". O bloco seguinte, sempre separado do anterior por um espaço em branco, nos introduz ao tempo: "Aunque parece que fue ayer, sucedió hace más de veinte años". De seu apartamento no edifício ministerial de Oslo, la Refractaria, o artista sanitário lembra, depois de contar até sessenta quatro vezes e se perder na quinta, da tela que pintou aos 14 anos por mandato paterno: "Matanza de cerdos en Vestlandet. Óleo sobre lienzo, 87 x 100. St Louis Art Museum".

A partir daí, temos uma cena cinematográfica que desvela paralelamente o ritual de sacrifício dos porcos e a confecção do quadro que o tornou conhecido como um artista promissor em Oslo, la Refrataria. Essa é a cena primária que nos coloca desde logo em terreno instável. A mesma trama com diferentes aparências é o que vemos na Incursión no 4, de Cuaderno de Pripyat (2012). Na verdade, uma cena é a versão da outra: os elementos são os mesmos, a matança sob o comando do pai, o banho com água fervente, os auxiliares, os ganchos, as facas, a amante do pai. Para ficar só na cena do banho, vale comparar as duas versões:

Al término de la faena, el padre de Nikolai, cubierto de sangre, se desnuda ante todos y su amante lo baña arrojándole cubetazos de agua perfumada con azeites vegetales. El hombre grita porque el agua está hirviendo. Su piel se pone roja, más oscura que una bandera, y grita, pide más. Natliya? Más agua, perra! [...] Con argumentos innecesarios, la corre a las patadas y no permite que ella lo seque. (Cuaderno de Prypiat)

Al término de la faena su padre, cubierto de sangre, había mirado al quadro durante unos minutos, sin decir palabra. Se desnudó a la vista de todos y la mujeramante lo baño, de pie, arrojándole cubetazos de agua hiviendo hasta hacerlo gritar. Con argumentos innecesarios, su padre no permitió que ella lo secara. (El artista sanitario)

Assim como outros artistas contemporâneos, Carlos Ríos manipula um universo que vai se tornando familiar a seus leitores: os abatedouros (seu primeiro livro Media Romana, de 2001, livro de poesia, começa com el matadero de Duisburgo e daí o tema do matadouro se dissemina ${ }^{1}$ ), a antropofagia, os mandatos paternos, os lugares exóticos, ou seja, distantes das fronteiras nacionais, as artes visuais (a instalação, em Manigua, as colagens em Cuaderno de Pripyat), os limites imprecisos entre poesia e prosa ( La salud de W.R. está incluído entre seus livros de poemas, mas é um relato sobre Wilhelm Roentgen, físico que descobriu os raios $X$ no final do século XIX e ganhou o Nobel de física em 1901; em El artista sanitário há claramente uma instabilidade entre a linha da prosa e o verso).

Neste último, o relato se arma em torno de um artista que come o que pinta e, mais, que só pinta quando come. Sempre sob o efeito de uma droga (el aceto filial, ou

\footnotetext{
${ }^{1}$ Vale lembrar que El matadero, de Estebán Echeverría, escrito de 1838 a 1840, antes do autor de La cautiva se exilar no Uruguai, é, segundo Cesar Aira, a "piedra basal de la narrativa argentina".
} 
seja, anidrido acético, como ficamos sabendo por uma nota de rodapé), o artista sanitário, que não tem nome, pinta os olayas que, novamente segundo explicação em uma nota de rodapé, são "un grupo semihumano confinado por los gobiernos centrales a los países helados". Depois de pintá-lo, o artista leva o modelo até um restaurante onde é preparado por um cozinheiro e comido. O ritual é o procedimento comum que compartilha com seu amigo pintor de Florencia del Elba: "Introducir la dentadura en esa carne para documentar / acción que debe leerse como escupir" (e aqui se percebe como a prosa dá lugar ao verso). O sacrifício termina com os cães roendo os ossos do olaya e com a comparação de todo o acontecimento com o ataque dos vikings ao monastério de Lindisfarne, em 8 de junho de 793, marco do início da era das invasões vikings à Europa. $O$ fragmento 2 se fecha com a frase que os monges cristãos escreveram depois do saque: A furare normannorum libera nos Domine (da fúria dos homens do Norte, livrai-nos Senhor), traduzida, também, em uma nota de pé de página.

Em Frutos extraños, Florencia Garramuño trata de pensar uma transformação no campo das práticas estéticas que têm a ver com um desbordamento de suas especificidades, com novos modos de organização do sensível, ou seja, com transgressões e expansões dos diversos meios e suportes que estariam propondo novas formas de comunidade. Seus exemplos vão de Mario Bellatin, João Gilberto Noll, Luiz Ruffato, a Nuno Ramos, Jorge Macchi, Rosangela Rennó. Aponta ainda para a importância das práticas das artes visuais que agregam em uma instalação práticas diversas - textos, imagem em movimento, fotografia, objetos - e para o enfraquecimento de noções como autonomia e campo. Reinaldo Laddaga também detecta uma transformação que atinge tanto as artes verbais (Laddaga 2007) quanto as visuais e que assinala um esgotamento do paradigma moderno. Segundo ele "no sabemos, verdaderamente, como hablar de proyectos como los que me interesa analizar: proyectos irreconocibles desde la perspectiva de las disciplinas - ni producciones de 'arte visual', ni de 'música', ni de 'literatura' ... - que, sin embargo se encuentran inequivocamente en su descendencia [...]" (Laddaga 2006). Há nos relatos de Carlos Ríos, por exemplo, em El artista sanitário e La salud de W.R. muitos traços dos sintomas desse mal estar "frente a cualquier definición específica o cualquier categoria de pertenencia en la qual comodamente instalarse". (Garramuño, inédito)

A exploração dos limites do nacional, como centro do espaço da elaboração ficcional, vai dando lugar a outros territórios, o que, segundo Florencia Garramuño, constitui um dos exemplos dos vários tipos de especificidade (nacional, pessoal, de gênero, literária): no caso de Bellatin, temos os relatos japoneses, chineses, muçulmanos, judeus; no caso de Bernardo Carvalho, a narrativa também desborda das fronteiras nacionais, Mongólia, China, Estados Unidos, Rússia. Em Carlos Ríos, desde Media Romana, os espaços da narrativa são quase sempre lugares exóticos, seja a África dos conflitos étnicos, a Ucrânia, do acidente com a Usina de Chernóbyl, a Alemanha de Wilhelm Roentgen, etc. Esses espaços, no entanto, são muitas vezes exóticos a si mesmos, desgeografizados, cenários estrangeiros que apontam para um não tempo e um não espaço, como afirma Bellatin em uma entrevista: 
na verdade, o sentido maior para que sejam personagens estrangeiros, para que apareçam como personagens estrangeiros, que pertencem a outras tradições literárias, é que todos estão fora do tempo e do espaço. No meu primeiro livro, os personagens estiveram fora do tempo e do espaço e o que faço nas diferentes obras é ir variando esse não tempo e esse não espaço, criando para os personagens, espécies de máscaras e personalidades diferentes. Há alguns personagens que aparentemente são japoneses e inclusive há alguns livros que o leitor pensa que estão ambientados no Japão, mas depois, o livro mesmo diz que aquilo não é o Japão.

Vale lembrar ainda Roland Barthes que começa $O$ império dos signos em uma via de duas mãos:

\begin{abstract}
Se eu quiser imaginar um povo fictício, posso dar-lhe um nome inventado, tratá-lo declarativamente como um objeto romanesco [...] Posso também, sem pretender nada representar, ou analisar realidade alguma (são estes os maiores gestos do discurso ocidental), levantar em alguma parte do mundo (naquele lugar) um certo número de traços (palavra gráfica e linguística), e com esses traços formar deliberadamente um sistema. É esse sistema que chamarei de: Japão. (Barthes 2007, p. 7)
\end{abstract}

Em El artista sanitario, a narrativa se passa, no início, na Noruega, deslocandose depois para o México. Os nomes dos lugares, usados muitas vezes como elementos sonoros, destacados, como a produzir um encantamento em ritmo de verso, reaparecem em diferentes momentos da narrativa como um refrão: Storgata, Osterhaus, Grubbegata. Há ainda um contraste entre o frio do lugar e palavras que apontam para algo quente: "Arde el siglo en Oslo, la Refractaria"; "en la colmena del fiordo arden los intestinos de Oslo, la Refractaria", etc, assim como as metáforas ligadas à comida e à digestão. E toda uma questão em relação aos animais, não só devido ao estatuto ambíguo dos olayas (os próprios mexicanos são comparados no último capítulo a eles: "[...] semejamtes a olayas".), quanto ao próprio artista sanitário que, no fragmento de número 10 derrapa na neve por causa de "sus pezuñas de cabra".

Outro traço importante na escrita de Carlos Ríos é uma indiferenciação entre prosa e verso, como na frase que alude ao procedimento que o artista sanitário compartilha com seu amigo: "Introducir la dentadura en esa carne para documentar / acción que debe leerse como escupir". Vale notar que a escrita passa da prosa à poesia exatamente no momento de nomear o procedimento do artista. La salud de W.R., uma novelita, foi publicada em uma coleção de poesia (todos os outros livros da coleção são livros de poemas). Desde Media Romana, essa convivência entre poesia e prosa acontece nos livros do autor. Lendo o último livro de Tamara Kamenszain, La novela de la poesía, Florencia Garramuño vê em sua escrita poética uma pulsão narrativa: "[...] es que el libro así ordenado hace evidente una pulsión que habitó la poesia de Tamara Kamenszain desde un comienzo [...]. Quiero nombrar esa pulsión, esa insistencia, que viene desde De este lado del mediterráneo [...] como el paso de prosa de la poesia de Tamara" (Garramuño, p.108). Poderíamos dizer que se Carlos Ríos concebe alguns de seus livros de poemas dentro desse mesmo espírito, em El artista sanitário o que vemos em vários momentos é "un paso de poesía", ou seja, uma transição da prosa ao verso tão sutil quanto a cena, citada em Santiago, de João 
Moreira Salles, da passagem da caminhada à dança em Roda da Fortuna, com Fred Astaire e Cyd Charisse. Uma passagem, um trânsito que assinala uma convivência, uma indiferenciação entre modos de fazer.

Outro ponto destacado tanto por Florencia Garramuño quanto por Reinaldo Laddaga é a relação da literatura com as artes visuais. Para Laddaga, "[...] algunos escritores latinoamericanos centrales [...] han publicado libros en los quales se imaginan [...] figuras de artistas que son menos los artífices de construcciones densas de lenguaje o los creadores de historias extraordinárias, que productores de 'espetáculos de realidad', empleados a montar escenas en las cuales se exhiben, en condiciones estilizadas, objetos y procesos de los cuales es difícil decir si son naturales o artificiales, simulados o reales" (Laddaga 2006, p.14). Segundo ele, toda literatura tem como objetivo a condição da arte contemporânea. É o que acontece, por exemplo, com Bellatin e suas instalações e performances. Vale lembrar, no entanto, a posição de Graciela Goldchluk ao se referir àqueles que qualificam Bellatin como artista em oposição a escritor: "mi apreciación es que en su caso lo que hay es un diálogo distanciado con estos movimientos, en tanto su proyecto se diferencia de otros a partir de su inscripción, que es siempre literária". (Goldchluk 2011) Poderíamos dizer o mesmo de Carlos Ríos.

Em seus textos, seguimos o fio, não só das artes contemporâneas, mas também do arquivo da história da arte. Se em Manigua descobrimos que a história que vai sendo narrada é uma instalação que expõe em uma galeria a morte de uma etnia, se em Media Romana, o poema termina com uma alusão à Lição de anatomia, de Rembrandt, em El artista sanitario temos um quadro como o centro do relato: a matança dos porcos na granja familiar. Segundo Robert Baldwin, o abate de porcos, bois, como um motivo artístico, tem uma larga tradição em contextos diversos do século XV ao XVII. Se ficarmos no campo da pintura holandesa, os exemplos são muitos: Rembrandt ( $O$ boi abatido, de 1655), Barent Fabritius, Joachim Beuckelaer, Hubert van Ravesteyn, para citar apenas alguns. Além disso, há toda uma alusão ao procedimento do artista sanitário que vai da antropofagia (ou seja, da relação entre comer e pintar) à imersão de suas mãos em água gelada antes de começar a pintar: "Con las manos rígidas pinta. El trazo inarticulado deja de ser un ejercício que depende del ojo". Em uma entrevista, Carlos Ríos afirma que "narrar una acción cualquiera es también, a su modo, el relato de una acción artística, de un proceso (y siempre vulnerable, inestable, un conjunto en trance de disociarse)". O que se narra, portanto, é um procedimento, um modo de fazer.

No quarto fragmento, o artista sanitário, paralisado pela inação, escreve: "Grito Silencioso No 133. Puente Kjerringstraumen. Calle Naranja (Osterhaus). Sudores, bestias en tropel. Sin cerdos no hay obra? 150 sarcófagos 'Knd', escala 1:1". Depois repete até decorar, jogando em seguida fora o que acabara de escrever. Entre parênteses lemos a explicação: "Hizo una promesa, la de no escribir más, desde que su amigo, el pintor radicado en Florencia del Elba, le ha dicho que en un siglo de fuego sólo las artes plásticas sobreviverán a la literatura". Todo esse fragmento descreve o processo de pintura desde a paralisia - "El artista sanitário puede quedarse días así, sin hacer nada, hasta que surge, descomunal y tensa, la estructura" - até que o traço 
surge na tela "como salido de una escena vegetal, el fruto de una prolongada elevación". O processo, então, consiste em uma despersonalização alcançada tanto com o mergulho das mãos em água fria quanto com o consumo da droga (el aceto filial). O objetivo é alcançar uma "pincelada impersonal".

Há uma certa precariedade nas novelitas de Carlos Ríos, que também podemos encontrar em Cesar Aira ou Mario Bellatin. São narrativas construídas com restos do real que o escritor vai catando na internet: nomes de personagens, fragmentos da história (no caso de El artista sanitário, da história da Noruega e do México), listas de palavras em línguas estrangeiras, restos do real constantemente reorganizados compondo novas constelações, ou seja, siempre una idéntica trama, con diferentes apariencias. Poderíamos dizer, com Laddaga, que se trata de livros do final do livro: "libros de la época en que lo impreso es un medio entre otros de transporte de la palabra escrita, y que aquí se quisiera que transportara esbozos que tuvieran el porte de aquello que se ha realizado bajo presión, bloques imperfectos, irregulares, como se fueran hechos por alguien que fuera fiel a esa otra fórmula: toda literatura aspira a la condición de la improvisación. Pero una improvisación que se realice con aquellos elementos que el escritor encuentra en torno suyo y que arregla en el instante. Porque toda literatura aspira a la condición de instantánea" (Laddaga 2007, p.15). Se em Aira a narrativa corre loucamente em direção ao final, se em Bellatin ela se compõe de fragmentos cuja conexão muitas vezes é precária, em Ríos ela vai se montando com pedaços de real que o escritor cata navegando virtualmente.

Entre as muitas insistências, temas que voltam em todos os livros, El artista sanitario traz ainda a figura paterna como um detonador da narrativa. Em Manigua, a viagem de Muthahi em busca da vaca para o nascimento irmão se realiza em função de um mandato paterno. Em El artista sanitario o pai aparece já no primeiro fragmento comandando a matança dos porcos, enquanto o filho pinta o quadro que o tornaria conhecido. É uma cena cinematográfica: depois do trabalho concluído, o pai do artista toma um banho de água fervente e ao olhar para o quadro diz: "Dios, es la mejor pintura que he visto em mi vida". Antes, porém, entre parênteses, o narrador nos mostra a relação do olhar do pai com a pintura: "En ese instante, el artista sanitario vio cómo las tonalidades rojas ascendían del quadro hacia los ojos de su padre: dos torrentes pastosos, a segundos de coagular, entrando por el hueco de sus órbitas". O pai habita a narrativa ainda em uma fotografia escolar que o artista mantém em seu apartamento em Oslo. Nela a mão esquerda do pai se apoia sobre o ombro do filho que, cada vez que a olha, sente uma "oscura debilidad". Aparece uma vez mais no oitavo fragmento quando o artista pinta uma rebelião dos olayas: "Su padre ingresa en el quadro con los compañeros de sindicato y rebanan en cien pedazos a los olayas insurrectos".

No final da narrativa, o artista, em um movimento de desterritorialização e reterritorialização, foge de Oslo por causa de uma revolta detonada a partir da adoração de falsos ídolos, nomeados como Yngve Ohlin e Oystein Aarseth. Conhecido como Euronymous, Aarseth era o guitarrista da banda norueguesa de black metal Mayhem e fundador do selo Deathlike Silence Productions. Ohlin era o vocalista da banda; suicidou-se em abril de 1991. Em 1993, Euronymous morre esfaqueado por 
Varg Vikernes, outro músico de black metal que, por causa do assassinato, cumpriu 16 anos de prisão. Enfim, a revolta faz com que o artista fuja do país, embarcando para o México onde se encontra com os muralistas mexicanos. Nos dois últimos fragmentos, então, o quadro que toma conta da narrativa é o mural que José Clemente Orozco pintou entre 1932 e 34 na Baker Memorial Library do Dartmouth College, em New Hampshire. São 24 painéis pintados ao longo de 300 m2. Em uma carta, Orozco explica o tema dos murais:

\begin{abstract}
Las razas de América están ahora tomando conciencia de su propia personalidad la cual emerge de dos grandes corrientes culturales, la indígena y la europea. El gran mito de Quetzalcóatl abraza ambas por su profética naturaleza, él como creador de la auténtica civilización del nuevo mundo, este tema tiene importancia para Dartmouth ya que no es un tema local sino continental, ya que la fundación de Dartmouth es anterior a la fundación de los Estados Unidos. (apud Acevedo, E. et ali, 2011, p.89)
\end{abstract}

O artista conversa com Orozco. A pergunta que ele dirige ao mestre muralista encerra a questão das origens: "En un inglés mal temperado [...] le pregunta a José Clemente Orozco si Quetzalcóatl fue un vikingo que llego a México por las gracias de un naufrágio". Os muralistas riem o que obriga o artista sanitário a contar a história que tinha ouvido de seu professor na prisão. Mas a história do artista sanitário deixa dúvidas na cabeça de Orozco: "Que el artista sanitario abrió un cauce en la cabeza de José Clemente Orozco, el más expresionista de los muralistas mexicanos, es um hecho". E o narrador nos dá a prova: "En un cuerpo del mural al fresco que el muralista de Zapotlán diseño para cubrir los interiores de la Biblioteca Blake, se observa a un enérgico Quetzalcoatl, de barbas largas, corpulento como un vikingo, lanzándose al mar en dirección al Este, encaramado en una balsa de serpientes". Mas ele mesmo contrapõe outra versão à origem viking dos astecas:

Quetzalcóatl fue al Mictlan a recoger los huesos preciosos para llevarlos al otro lado del Océano, oculto el linaje emplumado bajo la apariencia vikinga, con el propósito de que entre los pliegues del fiordo naciera, a imagen y semejanza, un Nuevo Ser.

O narrador, que conduz a história como o olho de uma câmera, se retira então, no melhor estilo dramático: " $y$ en este punto podríamos retirarnos y dejar que estos sujetos se afirmen y forjen, con el espéculo de su experiencia, el humor de sus sobresaltos y caprichos".

\title{
Bibliografia
}

ACEVEDO, E. et al. Mexico y la invención del arte latinoamericano, 1910-1950. México: Secretaria de Relaciones Exteriores e Dirección General del Acervo Histórico Diplomático, 2011.

BALDWIN, Robert. Thoughts on the slaughtered pig in renaissance and baroque art: from courtly cosmos to burger prosperity. In www.socialhistoryofart.com 
BARTHES, Roland. 0 império dos signos. Trad. de Leyla Perrone Moisés. São Paulo: Martins Fontes, 2007.

GARRAMUÑO, Florencia. Frutos extraños: ensayos sobre la inespecificidad en la estética contemporánea. Inédito.

GOLDCHLUK, Graciela en Actas del congreso, http://imagenesyrealismosleiden.files.wordpress.com/2012/01/lecciones-de-realismopara-una-liebre-muerta-sobre-la-obra-de-mario-bellatc3adn.pdf JASINSKI, Isabel. A fuga da escrita: entrevista com Mario Bellatin. Trad. de Nylcéa Teresa Siqueira Pedra. Bólide, Revista de literatura e arte, v. 1, Curitiba, mar/abr/mai 2013.

LADDAGA, Reinaldo. Estética de la emergencia: la formación de otra cultura de las artes. Buenos Aires: Adriana Hidalgo, 2006.

LADDAGA, Reinaldo. Espetáculos de realidad: Ensayo sobre la narrativa latinoamericana de las últimas dos décadas. Rosario: Beatriz Viterbo, 2007.

RÍOS, Carlos. El artista sanitario. Córdoba: Postales Japoneses, 2012.

Cuaderno de Pripyat. Buenos Aires: Entropía, 2012.

A la sombra de Chaki Chan. Maldonado, Uruguay: Trópico Sur, 2011.

Manigua. Buenos Aires: Entropía, 2009.

. La salud de W.R. Mar del Plata: Dársena3, 2007.

Media Romana. La Plata: El Broche, 2001.

Title: Notes on a vulnerable literature: El artista sanitário

Abstract: The narratives of Carlos Rios deliver us to a contemporary situation aimed at an exhausted modernist paradigm. The objective of this text is to consider Carlos Rios' strategies, to consider how he resets the sensible in a way that reveals a new idea of community: How to inhabit the world? How to relate to the animals? How to write a narrative?

Keywords: Latin-American literature. Lliterary theory. Narrative.

Recebido em: 09/10/2013. Aceito em 30/11/2013 